\title{
Monitoring urban growth around Rustenburg, South Africa, using SPOT 5
}

\author{
Naledzani Mudau ${ }^{1}$, Paidamwoyo Mhangara ${ }^{1}$, Michael Gebreslasie $^{2}$ \\ ${ }^{1}$ South African National Space Agency, Earth Observation, Pretoria, nmudau@ @ansa.org.za \\ ${ }^{2}$ School of Agricultural, Earth and Environmental Sciences, University of KwaZulu-Natal, \\ Durban
}

DOI: http://dx.doi.org/10.4314/sajg.v3i2.5

\begin{abstract}
Understanding urban spatial growth is critical for sustainable urban infrastructure and service planning. Urban growth information is an important input into predicting future land cover and land use change and sustainable growth management. Rapid urbanization has resulted in expanded urban land use and has led to population explosions in urban areas and undesirable environmental impacts in South Africa. This research is aimed at studying urban spatial growth of Rustenburg city in South Africa from 2007 to 2012 using temporal imagery acquired by Satellite Pour l'Observation de la Terra (SPOT) 5 satellite. Multi-temporal images acquired in 2007, 2009 and 2012 were used to assess urban spatial growth of Rustenburg. Post-classification change detection method was used to quantify urban growth. For the purpose of this study, only two classes, urban and non-urban land use classes, were mapped and assessed. The urban spatial growth between 2007 and 2009 was $16.8 \%$ while 8.7\% urban growth was observed between 2009 and 2012. The total spatial urban growth between 2007 and 2012 was 25.5\%. This information can be used by the municipal authorities and decision makers as input during urban and environmental planning.
\end{abstract}

\section{Introduction}

Urbanisation is an endemic phenomenon that is causing significant town planning and service delivery challenges globally. In most developing and emerging economies, urbanization is a result of an increase of population living in urban areas (WHO, 2010). Many studies point out that population growth in urban areas is a result of migration and natural urban demographic growth (Cohen, 2006; Samil and Bassan, 2006; Eckert, 2011; Bhatta 2010). The transformation of rural areas into urban areas has also been known to accelerate population growth rates in urban centres. Unsustainable urbanisation often results in poor environmental conditions, increased pressure on the current urban infrastructure and subsequently results in resource constraints (Institute for Sustainable Communities, 2013). Globally the number of urban dwellers is growing by nearly 60 million every year. India, 
China and emerging economies in Africa have experienced the highest rates of urban land expansion between 1970 and 2000 (Seto et al., 2011). Recent studies reveal that most of the global population growth will occur in smaller towns and cities in the developing countries in the next 30 years (Cohen, 2006; UNFPA, 2007; Seto et al., 2011). In Africa, one third of the population lives in urban areas and this figure is expected to rise by over 300 million between 2000 and 2030. The urbanisation rate of $1.21 \%$ is projected annually in Africa, (United Nations, 2011). In developing countries, urban population growth has exceeded the capacity of the cities to provide adequate basic services due to lack of understanding of future urban patterns and trends (Cohen, 2006).

A study by Lebone (2011) highlighted that currently two-thirds of the population in South Africa live in urban areas. The proportion of people living in urban areas in South Africa increased from 52\% in 1990 to $62 \%$ in 2011. Interestingly, smaller towns are experiencing the highest growth rates in South Africa owing to a growing economic activity. Polokwane, Rustenburg, Vanderbijlpark, Nelspruit, and Ekurhuleni are South Africa's five fastestgrowing urban areas, with average annual population growth rates of between $1.6 \%$ and $2.9 \%$ over the last decade (Ndebele, 2013). After 1991, there has been an extremely high increase of black and coloured populations in South African cities due to abolition of apartheid influx control legislation. Most of this population is settled into newly formed informal and formal settlements within or adjacent to the townships (Geyer et al., 2012). Tshikotshi (2009) attributes the rapid urbanisation witnessed in South African cities to a battery of postapartheid urban development polices introduced after 1994 to bring equity to marginalized population groups. Post-apartheid legislations such as the Housing White Paper of 1994, Constitution of 1996, Housing Act of 1997 and the 2005 Comprehensive Plan for Sustainable Human Settlement provided new policies guiding the provision of sustainable human settlements. Unmanaged urbanisation and lack of institutional framework for intersectional co-ordination in cities leads to service delivery problems, urban decay, health related issues, landscape fragmentation, encroachment into productive agricultural land, and unexpected urban spatial change (Atikinson and Marais, 2006). This subsequently results in new demands for services in urban areas in instances where the infrastructure is not developed and optimized to support the increased population. Understanding the dynamics of urban growth is therefore significant in urban land use planning (Soffianian et al., 2010).

Advances in remote sensing technology have provided researchers with remote sensing data with adequate spatial and temporal resolution to study urbanisation trends. Satellite remote sensing technology has been used successfully to study urbanization in many parts of the world. The most recent studies include: Las Vegas in USA (Xian et al., 2005), Amman in Jordan (Samil and Bussan, 2006), Baltimore in USA, (Zhou et al., 2008), Port Elizabeth in South Africa (Odindi et al., 2012), Shanghai in China (Linli and Jun 2012), Kampala in 
Uganda (Abebe, 2013) and Stockholm in Canada (Haas, 2013). Various image classification and change detection techniques are used to obtain urban land cover information and to assess spatial urban growth patterns over time. Pixel-based classification techniques are commonly used to classify land cover and land use in urban areas. These techniques classify an image pixel by pixel using algorithms to group pixels with similar spectral properties. There are a variety of supervised and unsupervised pixel-based classifiers such as ISODATA, maximum likelihood, minimum distance, spectral unmixing and neutral networks. Although pixel based classifiers are widely used they are often criticized for only exploiting the spectral domain without fully utilizing textural and spatial attributes such as shape (Blaschke et al., 2000). Unlike pixel-based analysis, object-oriented analysis classifies image objects which are created using a segmentation process. A number of segmentation techniques such as contrast split, contrast filter, chessboard based segmentation, multi-threshold, spectral difference and multi-resolution segmentation have been utilized to successfully partition image into meaningful objects. Using multi-resolution segmentation for instance, image objects are grouped in a manner that maximizes homogeneity within objects (Trimble, 2010). Based on the image objects, the object-oriented approach uses both textural and contextual information as well as spectral information to classify image objects with higher land cover classification accuracy (Gao et al., 2006). Recent studies show that object-oriented techniques are capable of achieving higher accuracies in extracting of land cover information compared to pixel based approaches (Qian et al., 2007; Matinfar et al., 2007).

To assess urban developments over time, change detection techniques are applied to multidate imagery. The techniques used for change detection analysis are divided into preclassification and post-classification. Pre-classification techniques apply various algorithms including image differencing, image ratioing, image regression, Vegetation Index Differencing, Principal Components Analysis and Change Vector Analysis to multi-date imagery to generate change and no-change maps (Singh, 2010). Post-classification techniques require the comparison of independently classified images (Shaoqing and Lu, 2008). The main advantage of post-classification change detection technique is the minimal impact of radiometric and geometric differences between the multi-date images. However, the accuracy of change detection results using this method depends on the accuracy of the classification results (Théau, 2011). The higher accuracy achieved using object-based classification method provides for a better means to post-classification change detection in urban areas as there is minimal misclassification of features than when using pixel based techniques (Zhou et al., 2008). Hafez (2011) evaluated change detection techniques for monitoring land use change and obtained higher accuracies for post-classification change detection compared to image differencing, image ratioing and Principal Component Analysis. The objective of this study was therefore, to quantity urban expansion in 
Rustenburg from 2007 to 2012 by applying object-oriented and post-classification change detection techniques on SPOT 5 imagery.

\section{Study area}

Rustenburg is located in $25^{\circ} 40^{\prime} 0^{\prime \prime}$ South, $27^{\circ} 15^{\prime} 0^{\prime \prime}$ East and has maximum elevation of $1,170 \mathrm{~m}$. This city is situated at the foot of the Magaliesberg mountain range in North West Province of South Africa and was considered as one of the fastest growing urban areas in South Africa in 2010 due to the economic impact of the world's three largest platinum mines which are located around this city. The economy of this city is closely linked to the economic spin-offs of platinum mining, with the sector contributing $77 \%$ of the city's Gross Geographic Product (GGP). Mines around the city contribute approximately $70 \%$ of the world's platinum production (Ololade, 2012).

Rustenburg has a population of 242892 (Statistics South Africa, 2013). The study area covers a total area of about $120 \mathrm{~km}^{2}$. Employment opportunities emanating from mining activities in this area attract people from other parts of South Africa and migrants from the Southern African region. The accessibility of Rustenburg from Gauteng, the most populated province in South Africa, also contributes to the high population growth of the city. This pull migration factor results in development of informal and formal settlements around the city. The geographic location of Rustenburg is shown in Figure 1. 


\section{STUDY AREA}

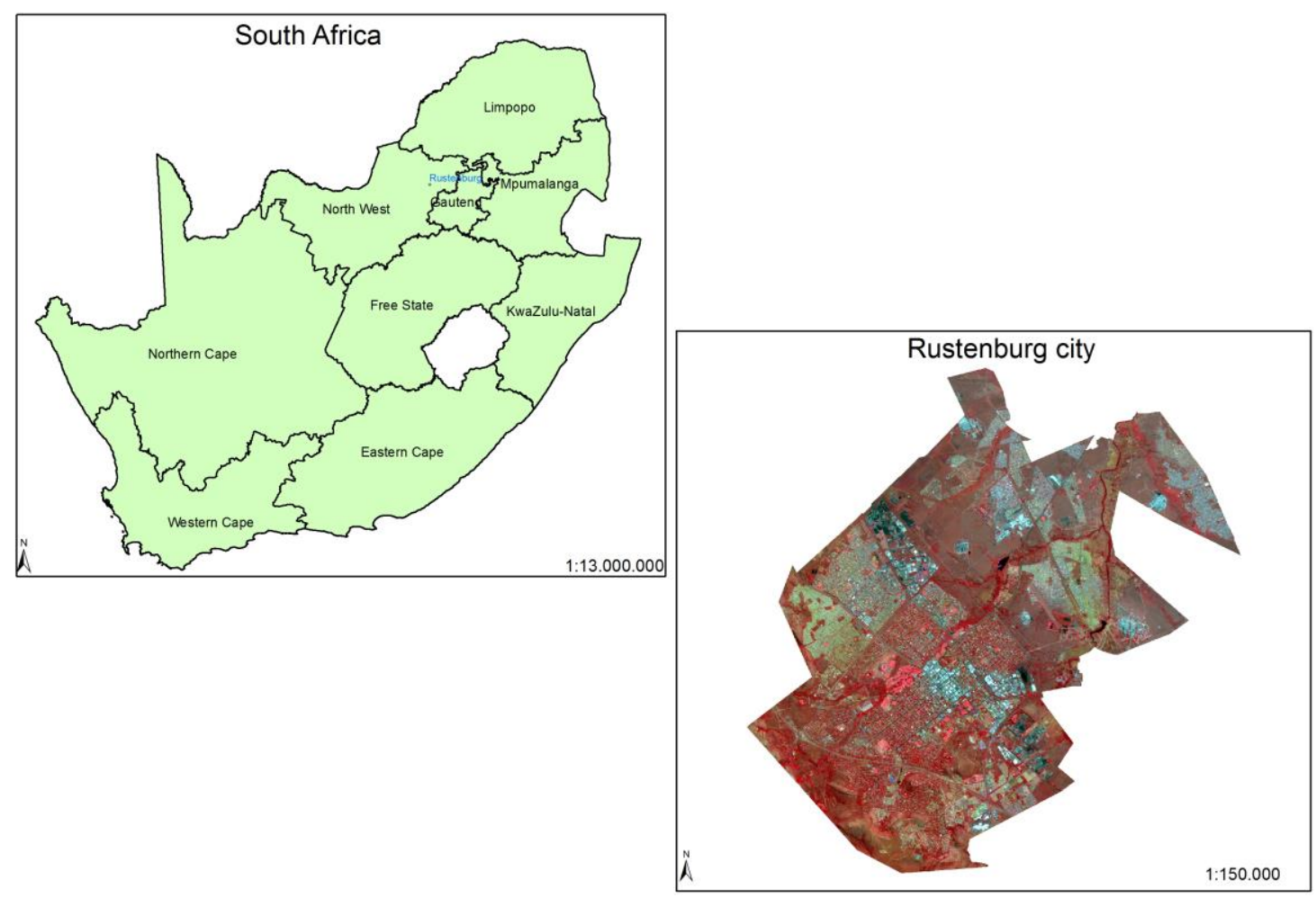

Figure 1: Study area

\section{Material and Methods}

\subsection{Remotely sensed data sources}

The SPOT 5 images used for the change detection were acquired on 17th April 2012, 27th May 2009 and 18th March 2007. The images were geo-rectified using $25 \mathrm{~cm}$ aerial photography and 20m Digital Elevation Model (DEM). The study area falls within one scene of SPOT 5. A panchromatic band with $2.5 \mathrm{~m}$ spatial resolution and four multispectral bands with $10 \mathrm{~m}$ spatial resolution were fused through an Intensity, Hue, and Saturation (IHS) transformation with a 4-3-2 band combination for Red-Green-Blue colour composite. A fused pan-sharpened image was then used for classification. This approach allows maximum spectral and textural distinction between urban areas and non-urban areas. Both images were masked to cover the study area to reduce the file size and processing time.

\subsection{Image classification and accuracy assessment}

For the purpose of the study, two classes, urban and non-urban were mapped. Urban areas were defined as densely built-up areas that are comprised of higher population density and characterized by human-made features in comparison to the surrounding rural area. Urban features discernable from SPOT 5 imagery include residential buildings, yards, pools, roads, 
and industrial, commercial and other urban land cover and land use features within built-up areas. Non-urban areas referred to vegetation covers, mines, water, bare/open land and other non-built up areas. Object Based Image Analysis was used to classify the image objects. A multi-resolution segmentation with a scale parameter of 35 and the colour value weight of 0.5 were used to generate image objects. These variables generated image objects representative of the most of urban areas with minimum confusion between urban and non-urban features. After segmentation, the image objects were classified using Standard Nearest Neighbour classifier which uses selected samples to classify the image objects. A representative number of samples were selected for both urban and non-urban features using visual image interpretation and with reference to $25 \mathrm{~cm}$ resolution aerial photography covering the study area. Once classified, the images objects that fall under the same classes were merged together using region grow functionality of eCognition Developer 8 software. The images were classified separately.

Accuracy assessment was performed to assess the accuracy of the classification results. Due to unavailability of high resolution reference data acquired in 2007, 2009 and 2012, available aerial photography acquired in 2010 was used to assess the accuracy of the classifications. 254 stratified random points were created and same point was identified using visual image interpretation on the aerial photography. Given that one 2010 aerial photograph was used for accuracy assessment we mitigated the errors by doing a stringent visual assessment to ensure that the test sample areas extracted from the 2010 aerial photographs were pseudo-invariant features discernable from the natural colour composites for 2007, 2009 and 2012.

\subsection{Change detection}

Post-classification change detection was used to quantify changes due to urbanization. Change detection analysis was done using ArcGIS software 10.1 using the overlay tool to identify urban areas that overlap in 2007, 2009 and 2012. Urban area features that did not overlap in both layers are defined as change. Urban growth was assessed by evaluating the changes in urban areas from 2007, 2009 to 2012.

\section{Results and Discussion}

This study shows that there was a significant land use transition from non-urban areas to urban areas. Figures 2, 3 and 4 show the spatial distribution of urban areas and non-urban areas in 2007, 2009 and 2012. The overall classification accuracies for 2007, 2009 and 2012 were $82.42 \%, 90.23 \%$ and $93.75 \%$ respectively. These significantly high accuracies obtained using object-based classifications are comparable to the results obtained during Baltimore land cover and change analysis study where the overall accuracies for 1999 and 2014 were $92.3 \%$ and $93.7 \%$ respectively (Zhou et al., 2008). 
The results show that extent of urban areas in 2007, 2009 and 2012 were $41.18 \mathrm{~km}^{2}$, $48.10 \mathrm{~km}^{2}$ and $52.28 \mathrm{~km}^{2}$ respectively. The urban areas increased by $6.92 \mathrm{~km}^{2}$ between 2007 and 2009 and $4.18 \mathrm{~km}^{2}$ between 2009 and 2012. This increase represents urban spatial growth of $16.8 \%$ between 2007 and 2009, $8.7 \%$ between 2009 and 2012 and a total spatial urban growth of $25.5 \%$ between 2007 and 2012. Figures 5 and 6 illustrate the changes in urban area over the years of assessment. The annual urban growth rate experienced in Rustenburg between 2007 and 2012 is $5.1 \%$. This annual growth rate is significantly higher than the 1.78\% urban growth experienced in Port Elizabeth, South Africa, between 1995 and 2000, 1.35\% in Amman in Jordan between 1996 and 2002 and 4.4\% in Kampala, Uganda, between 2003 and 2010 (Samil and Bussan, 2006; Zhou et al., 2008; Abebe 2013 ; Odindi et al., 2012). The annual growth rate almost doubled the maximum annual population growth of 2.9\% experienced in South Africa's fast urban areas in the last decade (SAIRR, 2013). Rustenburg's urban growth rate is also significantly higher than the average urbanisation rate of $1.21 \%$ projected annually in Africa by the United Nations.

This increase in urbanisation in Rustenburg is influenced by natural population growth, post-apartheid urban development, and increased influx of people from neighbouring provinces and countries and increased mining activities around the city. The effects of abolition of apartheid influx control can be seen in Rustenburg as urban growth is seen mainly around existing townships and informal settlements. The Upgrading Informal Settlement Programme (ISUP), as one of the post-apartheid development programmes, aimed at improving the livelihood of people living informal settlements by providing suitable housing and access to basic services, for instance resulted in massive construction of low cost houses. Proliferation of informal settlements within the city of Rustenburg also account for the elevated growth rate witnessed between 2007 and 2012. As an epicentre of platinum mining, a proportion of Rustenburg urban growth could be attributed to the growing mining activities. 


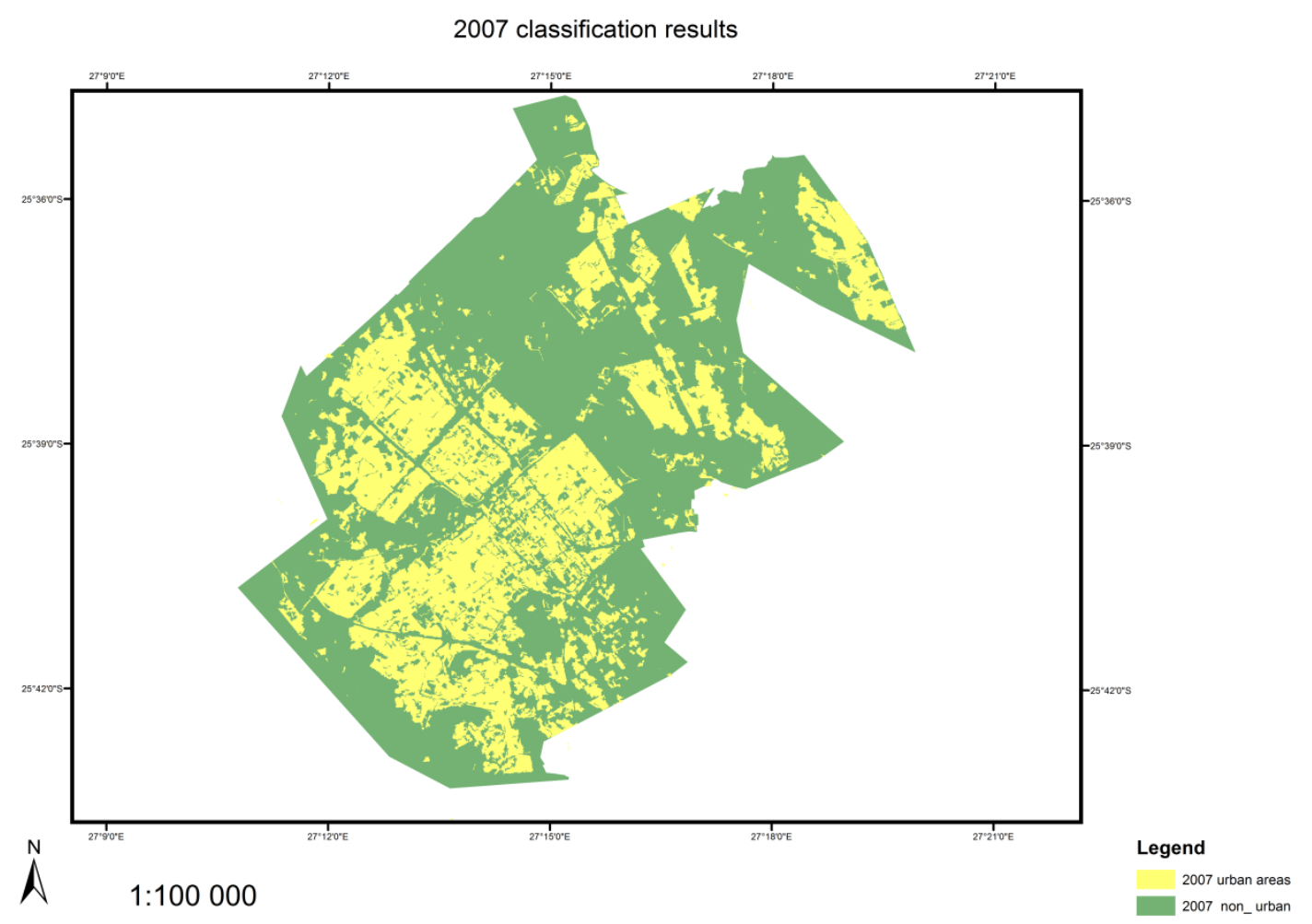

Figure 2: 2007 Classification results

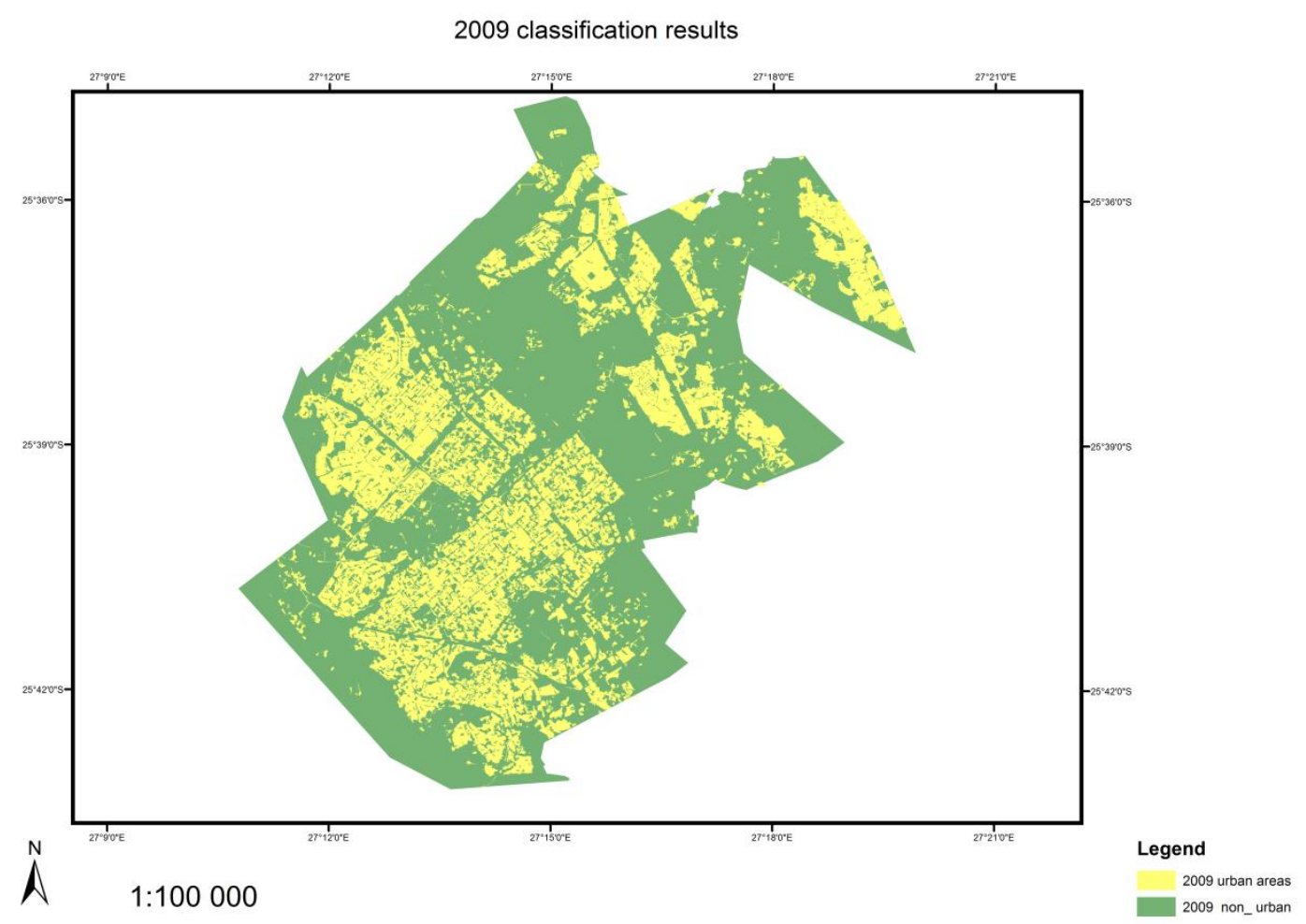

Figure 3: 2009 Classification results 


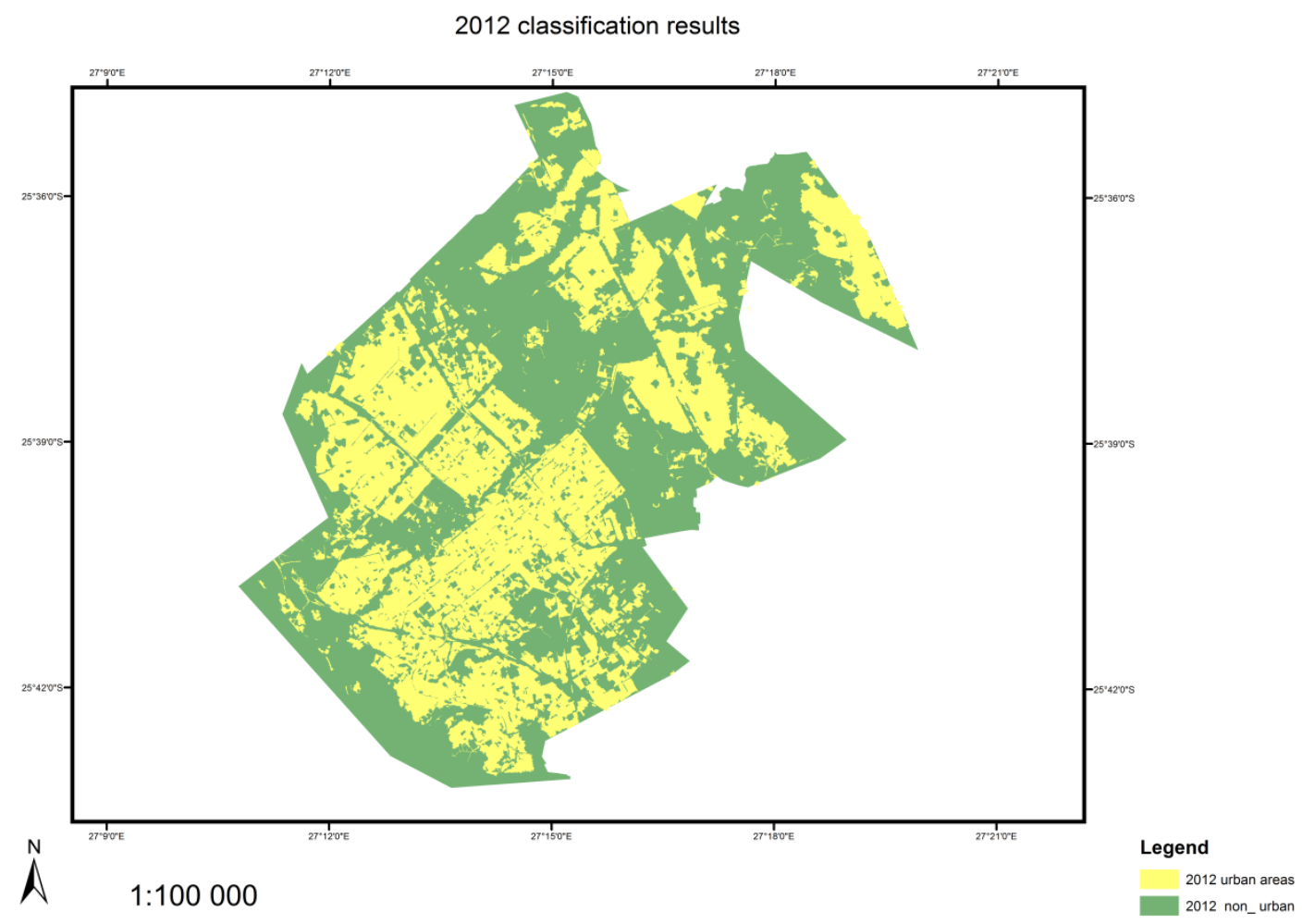

Figure 4: 2012 Classification results

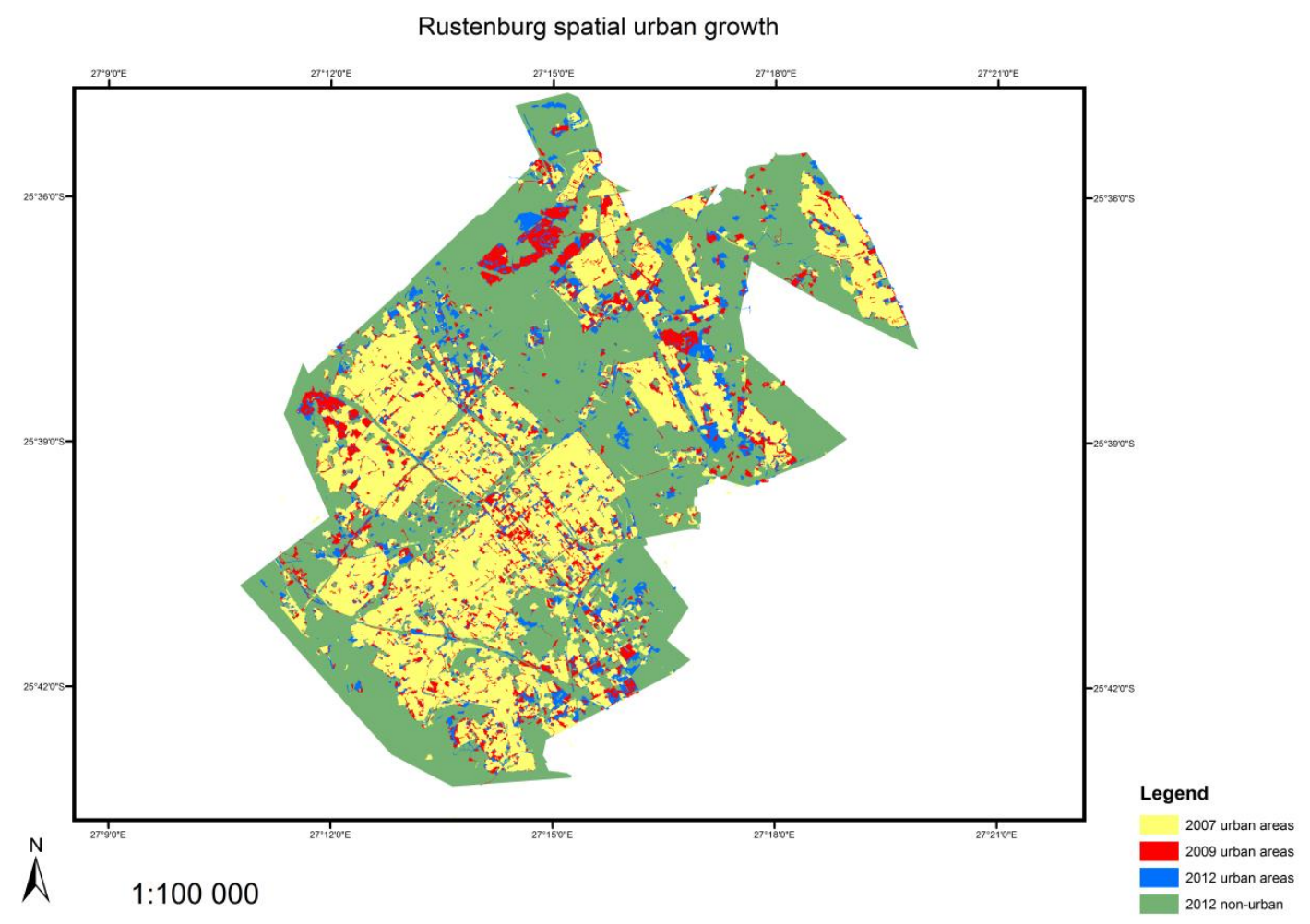

Figure 5: Spatial urban growth from 2007- 2009 to 2009 - 2012 


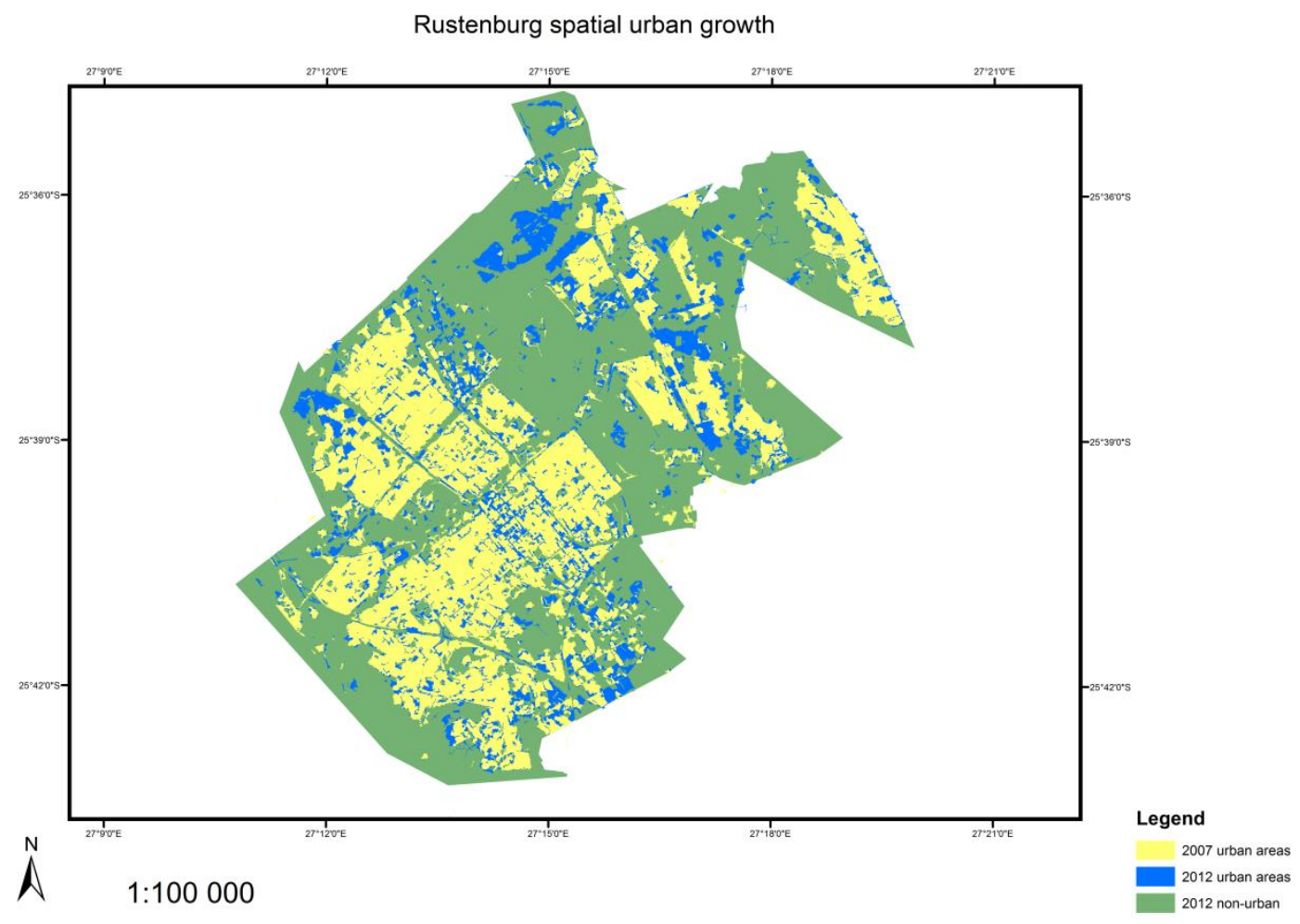

Figure 6: Spatial urban growth from 2007 to 2012

\section{Conclusion}

The study enabled the mapping of urban areas and an analysis of urbanisation in Rustenburg between 2007 and 2012. This study demonstrated the efficacy of object-oriented classification in delineating urban and non-urban features as shown by the high classification accuracies. Using a post-classification change detection technique the study showed that there was a significant urban expansion of $11.1 \mathrm{~km}^{2}$ in Rustenburg which represents $25.5 \%$ growth during a period of five years between 2007 and 2012. Rustenburg's rapid growth is higher than the growth rates experienced by other South African cities in the past decade. If unmanaged, urbanisation in Rustenburg could results in poor environmental conditions and increased pressure on the current urban infrastructure resulting in resource constraints. This study demonstrates the value of satellite imagery in examining urbanisation trends in growing cities. The urbanization spatial trends established in this study will provide valuable information required for municipal planning in Rustenburg city. 


\section{Reference}

Abebe G, 2013, 'Quantifying urban growth patterns in developing countries using remote sensing and spatial metrics: A case study in Kampala, Uganda', Master's thesis, Faculty of Geo-information science and Earth observation, University of Twente.

Atikinson D, Marais L, 2006, 'Urbanisation and the Future Urban Agenda in South Africa', in Udesh Pillay, Richard Tomlinson Ed, Jacques Du Toit (eds), Democracy and Delivery: Urban Policy in South Africa, HSRC Press.

Bhatta B, 2010, 'Causes of urban growth and sprawl', in Advances in Analysis of Urban Growth and Sprawl from Remote Sensing Data, Springer-Verlag Berlin Heidelberg.

Blaschke T, Land S, Lorup E, Strobl J, Zeil P, 2000, 'Object oriented image processing in a GIS/Remote sensing environment and perspective for environmental applications', in A. Cremers and K. Greve (eds) Environmental Information for Planning, Politics, and the Public, Marburg: Metropolis Verlag.

Cohen B, 2006, 'Urbanization in developing countries: Current trends, future projections, and key challenges for sustainability', Elsevier, vol 28, pp. 63-80.

Eckert S, 2011,'Urban expansion and its impact or urban agriculture-Remote sensing based change analysis of Kizinga and Mzinga valley - Dar Es Salaam, Tanzania', proceeding at European Association of Remote Sensing Laboratories, Ghent, Belgium, 22-24 September 2011, pp 42-55, EARSeL eProceedings.

Gao Yan, Mas J.F, Maathuis B.H.P, Zhang X, Vamn Dijk P.M, 2006, 'Comparison of pixel-based and object image classification approach-a case study in a coal fire, Wuda, Inner Mangolia, China', International Journal of Remote Sensing, vol 27, pp. 4040-4041.

Geyer Jr H.S, Geyer H.S, du Plessis D.J, 2012, 'Differential urbanisation trends in South Africaregional and local equivalents', Environment and Planning, vol. 44, pp. 2940-2956.

Haas J, 2013 'Remote Sensing of Urbanization and Environmental Impacts', licentiate thesis, Department of Urban Planning and Environment, Royal Institute of Technology.

Hafez A, 2011, 'Evaluation of change detection techniques for monitoring of land cover changes: A case study in New Burg El-Arab area', Alexandra Engineering Journal,vol 50, pp. 187-195.

Institute for Sustainable Communities, 2013, 'Urbanization, Infrastructure and Economic Growth In Southeast Asia', http://www.iscvt.org/news/urbanization-infrastructure-and-economic-growth-inasia/.

Lebone K, 2011, More people living in urban areas than ever before, South African Institute of Race Relations, 24 January, http://www.sairr.org.za/media/media-releases/Urbanisation\%20\%2024\%20January\%202011.pdf/view

Linli C, Jun S, 2012, 'Urbanization and its environmental effects in Shanghai, China', Elsevier, Urban Climate, vol. 2, pp 1-15.

Matinfar H.R, Sarmadian F, Alavi Panah K and Heck R.J, 2007, 'Comparisons of Object-Oriented and Pixel-Based Classification of Land Use/Land Cover Types Based on Lansadsat7, Etm+ Spectral Bands (Case Study: Arid Region of Iran)', American-Eurasian Journal of Agricultural \& Environmental Sciences', vol. 2, no 4, pp. 448-456.

Ndebele T, 2013, 'South Africa goes with the urbanisation flow', South African Institute of Race Relations, 22 January 2013, www.sairr.org.za/media/media-releases/Urbanisation.

Odindi J, Mhangara P, KakembonV, 2012, 'Remote sensing land-cover change in Port Elizabeth during South Africa's democratic transitions', South African Journal of Science, vol. 108, no 5, pp. 17. 
Ololade O, 2012, 'Evaluation of the Sustainability and Environmental impacts of Mining in the Rustenburg region', $\mathrm{PhD}$ thesis, Faculty of Science, University of Johannesburg, https://ujdigispace.uj.ac.za/handle/10210/8087.

Qian J, Zhou Q, Hou Q, 2007, 'Comparison of pixel-based and object -oriented classification techniques for extracting built-up areas in aridzone', Updating Geospatial Databases with Imagery \& 5th ISPRS Workshop on DMGISs, Urumchi, Xingjiang, China, August 2007, ISPRS proceedings XXXVI/4-W54, pp 163-171. http://www.isprs.org/proceedings/XXXVI/4-W54/papers/163-171.pdf.

Samil R and Bassan S, 2006, 'Satellite monitoring of urban spatial growth in the Amman Area, Jordan, ' Journal of Urban Planning and development, vol. 132, no 4, pp. 211-216.

Seto K, Fragkias M, Güneralp B, Reilly M, 2011, 'A Meta-Analysis of Global Urban Land Expansion', PlosOne, vol. 6, no 8, pp. 1-9.

Shaoqing Z, Lu X, 2008,'The comparison of three methods of remote sensing image change detection', The International Archives of the Photogrammetry, Remote Sensing and Spatial Information Sciences,. Beijing, 23-11 July 2008, ISPRS proceedings vol. XXXVII Part B7, http://www.isprs.org/proceedings/XXXVII/congress/7_pdf/10_ThS-18/12.pdf.

Singh A, 2010, 'Digital change detection techniques using remotely-sensed data', International Society for Photogrammetry and Remote Sensing, vol. 10, no 6, pp. 989-1003.

Soffianian A, Ahmadi M, Nadoushan, Yaghmaei L and Falahatkar S, 2010, Mapping and Analyzing Urban Expansion Using Remotely Sensed Imagery in Isfahan, Iran. World Applied Sciences Journal, vol. 9, no 10, pp. 1370-1378.

Statistics South Africa, 2013, Census 2011, http://beta2.statssa.gov.za/.

Théau J, 2011, 'Change detection', in Wolfgang Kresse and David Danko (eds), Springer Handbook of Geographic Information, Springer.

Trimble, 2010, 'eCognition Developer 8.64.0 user guide', Trimble Germany GmbH, pp. 31, 54-57.

Tshikotshi V, 2009,' The Challenges of Eradicating Informal Settlements in South Africa by 2014The Case of Seraleng Sustainable Human Settlement, Rustenburg Local Municipality, North West Province', Master's thesis, Faculty of Engineering and Built Environment, University of Witwatersrand, http://wiredspace.wits.ac.za/bitstream/handle/10539/8319/THe\%20Challengers\%20of\%20Eradicating \%20Informal\%20Settlements\%20In\%20SA\%20by\%202014.pdf.

United Nations Population Fund (UNFPA), 2007, 'Linking population, poverty and development; Urbanisation: A majority in Cities', http://www.unfpa.org/pds/urbanization.html.

WHO, World Health Organization, 2010, 'Urbanisation and Health', Geneva.

Xian G, Crane M, McMahon C, 2005,' Assessing urban growth and environmental change using remotely sensed data', Pecora 16 in global priorities in land remote sensing, Sioux Falls, South Dakota, 23 - 27 October 2005, ASPRS proceedings, http://www.asprs.org/a/publications/proceedings/pecora16/Xian_G.pdf.

Zhou W, Troy A and Grove M, 2008, 'Object-based Land Cover Classification and Change Analysis in the Baltimore Metropolitan Area Using Multitemporal High Resolution Remote Sensing Data', Sensors, vol. 8, no 3, pp 1613-1636. 